\title{
Intercâmbios educacionais e diversidade cultural: implicações para o ensino de português para falantes de outras línguas
}

\section{Educational Exchanges and Cultural Diversity: Implications for Teaching Portuguese for Speakers of Other Languages}

Maria Helena da Nóbrega*

Universidade de São Paulo

São Paulo - São Paulo / Brasil

RESUMO: O crescimento dos intercâmbios estudantis em universidades brasileiras amplia a heterogeneidade cultural nos cursos de português para falantes de outras línguas. Este artigo analisa as implicaçōes estruturais e pedagógicas decorrentes desse contexto multicultural e plurilinguístico. Pesquisa qualitativa com 25 alunos estrangeiros matriculados em curso de português para estrangeiros de universidade pública comprova essa diversidade cultural e linguística. Objetivando mapear o perfil desses alunos, a metodologia recorre a questionário, notas de campo e diário. A análise dos dados demonstra a necessidade de novas configuraçōes nas práticas pedagógicas, bem como adaptações no espaço físico escolar. Para além dos aspectos linguísticos, a proposta enfatiza a necessidade de despertar sensibilidade para questóes culturais e interculturais.

PALAVRAS-CHAVE: intercâmbios estudantis, diversidade cultural, português para falantes de outras línguas.

ABSTRACT: The increase of international student exchanges at Brazilian universities broadens cultural diversity in courses of Portuguese for speakers of other languages. This paper examines structural and pedagogical consequences arising from such multilingual and multicultural contexts. A qualitative survey of 25 foreign students enrolled in a Portuguese course for foreigners in a public university proves this cultural and linguistic diversity. In order to map the profile of these students, the methodology adopts questionnaire, field notes and research diary. Data analysis demonstrates the need of new settings in pedagogical practices, as well as adjustments in school environment. Apart from linguistic aspects, the proposal emphasizes the need to raise awareness about cultural issues, especially intercultural ones.

KEYWORDS: student exchanges, cultural diversity, Portuguese for speakers of other languages.

*mhn135@gmail.com 


\section{Introdução}

Jørgen e Rikke estão no voo Copenhagen-São Paulo. Vão estudar durante um ano em universidades brasileiras. Ambos têm experiência em viagens internacionais, mas nunca estiveram na América Latina e nem moraram fora da Dinamarca. Jørgen está exultante: vai finalmente conhecer o Brasil, ouvir ao vivo as músicas de que tanto gosta e comprovar o que viu nos filmes. Encorajado pelo aprendizado que teve no curso de língua portuguesa na Universidade de Aarhus, Jørgen puxa conversa com um grupo de brasileiros. Rikke se mantém distante: ela não fala português e não tem nenhuma motivação especial para esse intercâmbio. As catorze horas de viagem seguem cheias de expectativas, planos, medos, ansiedades nem sempre compartilhadas. Eles se separam no aeroporto de Guarulhos: Rikke está matriculada em uma instituição em São Paulo; Jørgen vai estudar em Salvador. $\mathrm{Na}$ apressada despedida em meio ao estranhamento da chegada, eles não se dão conta de que morar em outro país demanda ressignificação de si mesmo: é preciso reinventar-se!

Esses dois personagens fictícios ilustram as viagens internacionais de intercâmbio estudantil e são comumente tratados na literatura vigente como sojourners: pessoas que voluntariamente moram de seis meses a cinco anos em uma nação e depois retornam a seu país de origem (BURNETT; GARDNER, 2006).

Este artigo trata das viagens de intercâmbio estudantil, originadas no início do século XX (SCHAUER, 2009) e intensificadas em sua última década, e das implicaçōes que isso acarreta ao ensino de português para falantes de outras línguas (PFOL). Tomando como base teorias socioculturais (LANTOLF, 2004; SCHIEFFELIN; OCHS, 1986), analisa-se a diversidade cultural presente nas universidades brasileiras contemporâneas.

Além disso, o tema dos intercâmbios educacionais requer uma abordagem interdisciplinar, pois envolve conceitos interculturais, identitários e linguísticos. Essa imbricação temática, por si só, situa a pesquisa na área da linguística aplicada.

O texto traça um panorama das viagens internacionais para estudo, hoje fortemente integradas ao processo de internacionalização das universidades públicas e privadas. $\mathrm{O}$ cenário de mobilidade estudantil revela dados que demonstram a posição vantajosa do Brasil na escolha dos estudantes. Disso decorre o aumento no número de alunos estrangeiros nas instituições de ensino superior (IES) brasileiras. Vindos de todas as partes do mundo, esses alunos ampliam a heterogeneidade e trazem perspectivas interculturais (KIM, 2009) para todo o contexto escolar. 
Pesquisa qualitativa realizada em IES pública, no interior do estado de São Paulo, comprova a diversidade cultural em curso de PFOL. A metodologia utiliza i) questionário, ii) notas de campo, redigidas a partir de anotaçóes feitas durante as aulas e reelaboradas posteriormente em iii) diários de pesquisa. Tendo o consentimento dos sujeitos pesquisados, os resultados revelam o conhecimento desses alunos em relação à língua e cultura ao chegarem ao Brasil, bem como as expectativas em relação à aprendizagem ou aprimoramento do idioma.

Por último, averígua-se o ensino de PFOL frente a esse novo cenário e conclui-se com reflexōes sobre o caráter determinante que a cultura tem no modo de agir de professor e alunos, bem como nos processos de ensino e aprendizagem.

\section{Internacionalização educacional}

As políticas de internacionalização, que objetivam fomentar ações de desenvolvimento científico e tecnológico, concretizam-se principalmente em atividades de cooperação internacional. No entanto, "é possível observar que, originalmente, no período medieval, a universidade tinha um forte caráter internacional e que, como consequência da construção dos Estados nacionais, sofreu um processo de nacionalização" (KRAWCZYK, 2008, p. 42).

Essas fronteiras nacionalistas, fincadas também na produção científica, criaram o processo de internacionalizaçăo da educaçăo superior, que se intensificou mundialmente nos últimos anos, tanto nas IES públicas como nas privadas. É por isso que alguns autores atrelam o conceito de internacionalização à globalização.

Marginson e Rhoades (2002) conceituam Internacionalização como a globalização do ensino superior, o desenvolvimento do aumento de sistemas educacionais integrados e as relações universitárias além da nação. Estes autores conceituam também Capitalismo acadêmico, que identifica uma tendência global de privatização na educação superior, com todas as características inerentes, inclusive com destaque ao lucro. (MOROSINI, 2006, p. 116, grifos do original)

O incentivo aos estudos internacionais gerou transformaçôes nas práticas adotadas pelas IES. A Declaração de Bolonha, de 1999, assinala a tentativa de formar uma estrutura comum nos cursos de graduação e pós-graduação da comunidade europeia, facilitando a validação dos diplomas e o trânsito de docentes e discentes naquela região. ${ }^{1}$

${ }^{1}$ http://www.ond.vlaanderen.be/hogeronderwijs/bologna/about 
O Mercosul também já iniciou políticas educacionais que visam à integração das IES.

O processo de integração universitária no Mercosul vem se dando da mesma forma que no caso da UE: de cima para baixo e focalizado principalmente na equivalência dos sistemas universitários - pela padronização curricular -, buscando melhores condições de empregabilidade e de competitividade regional no âmbito internacional. (KRAWCZYK, 2008, p. 44)

Embora apresente aspectos positivos inegáveis, como o estabelecimento de redes de pesquisa e a preparação de profissionais para atuar em mercados culturais diversos e em permanente transformação, os processos de internacionalização vêm sofrendo fortes críticas na atualidade. Uma delas é em relação ao relacionamento assimétrico, que mantém a subserviência dos países periféricos: é preciso criar relações bilaterais, nas quais o Brasil também divulgue a ciência, tecnologia e cultura. Fora isso, critica-se também a sobreposição da influência econômica em detrimento da qualidade acadêmica (KIM, 2009; MOROSINI, 2006).

No Brasil os dados atuais mostram que a internacionalização ocorre de forma diferenciada em cada IES, não havendo ainda um programa de integração e aprimoramento dos procedimentos. Em decorrência disso, pesquisadores que têm contatos no exterior procuram sanar problemas estruturais, financeiros, culturais e linguísticos por meio de cooperação informal, na qual os compromissos são firmados em termos de projetos específicos. São ações individuais que vão pouco a pouco sendo integradas aos planos de ação das IES. O caminho é longo, mas tudo indica que estamos na direção certa, sobretudo se as propostas concentrarem-se na qualidade, conforme Morosini: "A internacionalização da educação superior frente à expansão quase que desordenada do sistema e à complexidade instituída, necessita, urgentemente, de estudos e políticas públicas que freiem a perspectiva mercadológica e contribuam para a qualidade acadêmica social" (2006, p. 107-108).

Ao lado de práticas como projetos de pesquisa, associações, publicações conjuntas com pesquisadores estrangeiros, as viagens educacionais ao exterior são a parte socialmente mais visível do processo atual de internacionalização das universidades, embora elas não tenham se iniciado na sociedade contemporânea. 


\section{Intercâmbios estudantis}

Desde a criação das primeiras universidades ocidentais - Paris, Bolonha, Oxford -, sempre houve viagens estudantis internacionais com o propósito de consolidação e disseminação do conhecimento.

Em 1911, a Société D’Échange International des Efants et de Jeunes Gens pour L'Études des Langues Étrangéres ${ }^{2}$ enviou 280 estudantes ao exterior (SCHAUER, 2009). O programa europeu Erasmus, fundado em 1987, já possibilitou os estudos em universidades de 31 países para 1,9 milhões de estudantes (SCHAUER, 2009). As cifras têm aumentado desde os primeiros anos do século XXI, quando houve um crescimento de 50\% na mobilidade dos estudantes, entre 2000 e 2005 (KIM, 2009).

O Brasil tem se esforçado para acompanhar essa tendência mundial e vem continuamente lançando programas de incentivo à cooperação científica internacional, tanto para alargar as relaçôes acadêmicas como para divulgar a ciência, cultura e tecnologia brasileiras no exterior. Em 2011, por exemplo, o governo federal lançou o Programa Ciência sem Fronteiras, que prevê até 75 mil bolsas de intercâmbio para alunos da graduação e pós-graduação nos próximos quatro anos. ${ }^{3}$

Além de investir no intercâmbio de docentes, discentes e pesquisadores brasileiros, o Brasil também desfruta de momento extremamente favorável no cenário internacional. $\mathrm{Na}$ imprensa é fácil deparar-se com notícias promissoras à posição da economia brasileira atual, e essa valorização atinge também a cultura e a língua. "Se você quer um retorno adequado ao seu investimento, a melhor língua para aprender é o português do Brasil”, ${ }^{4}$ escreveu Helen Joyce (2012, tradução minha), correspondente em São Paulo da revista The Economist.

Matérias desse teor, em revistas de projeção mundial, contribuem para o aumento no número de estrangeiros que escolhem o Brasil para estudar ou trabalhar, de forma temporária ou permanente. O Ministério da Justiça quantifica esse aumento em $57 \%$ em 2011, totalizando 1,5 milhão de pessoas (OKUMURA, 2012). O fato auspicioso é que a língua portuguesa vive

\footnotetext{
${ }^{2}$ Sociedade para o Intercâmbio Internacional de Crianças e Jovens para Estudos de Língua Estrangeira.

${ }^{3}$ http://capes.gov.br/bolsas/bolsas-no-exterior/ciencia-sem-fronteiras

4 "If you want a decent return on your investment, says Helen Joyce, the best language to learn is Brazilian Portuguese...".
} 
momento de expansão sem precedentes, o que se comprova no aumento de cursos para estrangeiros no Brasil e no exterior (NÓBREGA, 2011).

A pesquisa relatada a seguir exemplifica a diversidade cultural presente nas aulas de PFOL, além de destacar qual o interesse básico desses alunos na aprendizagem da língua e da cultura.

\section{Contexto da pesquisa}

Ambicionando atrair cada vez mais alunos estrangeiros, as IES criam mecanismos de ajuda aos recém-chegados, com orientaçôes sobre visto de permanência, seguro-saúde, carteira de estudante, acomodação etc. Parte importante dessa política de sedução é o oferecimento de cursos de língua portuguesa, para ajudar esses alunos a integrar-se mais rapidamente na cultura local, além de possibilitar participação ativa e crítica nas atividades acadêmicas. Esse foco funcional/instrumental norteou a criação do primeiro curso de Português para Estrangeiros em IES pública no interior do estado de São Paulo, onde a pesquisa, de viés qualitativo, buscou traçar o perfil dos estrangeiros que vêm estudar nessa unidade da IES, identificando principalmente o país de origem e o conhecimento da língua alvo que eles tinham (ou não) antes da chegada ao Brasil.

\section{Metodologia e sujeitos}

A metodologia adotou questionário, notas de campo e diários de pesquisa, escritos por mim, como professora-pesquisadora. O questionário foi aplicado no ato de matrícula, ou seja: os alunos responderam-no individualmente, tendo como base as instruçôes escritas de orientação das respostas. Os comentários objetivos ou notas de campo, anotados na urgência da sala de aula, foram submetidos à reflexão posterior, e disso resultaram os registros no diário.

Os sujeitos participantes, devidamente notificados sobre a pesquisa, foram alunos das duas primeiras turmas de Português para Estrangeiros, disciplina oferecida em 2009. No primeiro semestre, houve doze alunos matriculados, e no segundo, treze. Desse total de 25 alunos, dezessete eram do sexo feminino, e oito, do masculino. As idades variaram entre 22 e 39 anos. Todos eram alunos regulares da IES: dez cursavam graduação e quinze, pósgraduação. O período de estada no país varia de acordo com a finalidade dos estudos: os de graduação ficam de seis meses a um ano, enquanto os da pósgraduação permanecem no país de um a quatro anos. 


\section{Dados: foco na diversidade}

Parte das questôes do questionário busca mapear a nacionalidade dos participantes, o conhecimento de língua portuguesa ao chegar ao Brasil e o interesse específico em relação ao curso.

A ênfase nessas questóes se justifica pela necessidade de identificar a diversidade cultural das turmas e o grau de proficiência dos alunos, de forma a criar atividades didáticas desafiadoras. Além disso, o diagnóstico dos interesses permite personalizar as propostas, acompanhando uma das tendências do ensino de línguas contemporâneo.

A tabela a seguir situa os participantes em relação ao país de origem.

TABELA 1

Nacionalidade dos alunos estrangeiros

\begin{tabular}{lc}
\hline País & Número de alunos \\
\hline Argentina & 2 \\
Bolívia & 1 \\
Estados Unidos da América & 1 \\
Finlândia & 2 \\
França & 5 \\
México & 4 \\
Panamá & 3 \\
Peru & 6 \\
Suíça & 1 \\
\hline
\end{tabular}

Fonte: Dados da pesquisa.

As duas turmas analisadas dão mostras claras da diversidade cultural que precisa ser enfrentada pelo professor de PFOL. Trata-se de um estudo de caso, o que torna os dados retratos específicos das duas turmas analisadas. No entanto, a procedência de países variados existe em outros grupos de estrangeiros nas IES, e isso sugere que tendências verificadas em outras turmas podem confirmar os resultados deste estudo de caso.

O gráfico abaixo revela a exposição formal à língua portuguesa antes da vinda ao Brasil, dado obtido em pergunta feita no questionário: "Você fez curso de língua portuguesa antes de vir ao Brasil?” 


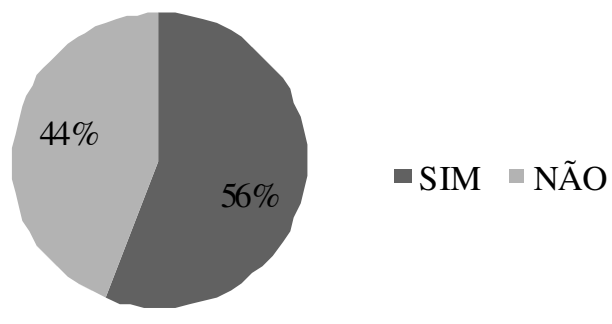

FIGURA 1 - Alunos que cursaram língua portuguesa antes de vir ao Brasil Fonte: Dados da pesquisa.

A duração desses cursos, realizados em escolas privadas de idioma, centros de línguas das universidades no exterior ou com professores particulares, varia de três meses a dois anos e meio, o que aponta para uma grande heterogeneidade no domínio linguístico ao iniciarem a disciplina de PFOL no Brasil.

Perguntados sobre os objetivos atuais em relação ao estudo da língua portuguesa, ou seja, as razões que justificam a matrícula no curso de PFOL, os alunos demonstraram os interesses abaixo.

TABELA 2

Objetivo dos estrangeiros no curso de PFOL

\begin{tabular}{lc}
\hline Interesse no curso de PFOL & Número de alunos \\
\hline Aprender português & 7 \\
Aprimorar conhecimento linguístico & 6 \\
Conhecer a cultura brasileira & 4 \\
Obter o certificado Celpe-Bras & 1 \\
Aprender redação acadêmica & 7 \\
\hline
\end{tabular}

Fonte: Dados da pesquisa.

A quantidade de alunos que frequentaram cursos de português antes do intercâmbio no Brasil (56\%) é bastante próxima da porcentagem de alunos que não frequentaram (44\%). Isso se traduz em interesses bastante diversificados quando eles se matricularam no curso de PFOL: alguns queriam aprender o básico da língua (28\%), enquanto outros revelavam proficiência linguística que os motivava à prática da linguagem acadêmica, tanto no aspecto redacional como na apresentação de comunicações orais. Dado curioso é o fato de quatro alunos terem explicitado o interesse em conhecer a cultura brasileira. 
Assim, apenas 16\% desses universitários parecem perceber a importância dos estudos culturais na aprendizagem da língua alvo.

\section{Análise dos resultados}

$\mathrm{O}$ aspecto mais acachapante revelado pelos dados é o caráter francamente heterogêneo das turmas: vindos de diferentes países, os alunos de PFOL também apresentam interesses variados na aprendizagem de língua portuguesa. As diferenças também existem no conhecimento linguístico prévio da língua alvo antes de matricular-se no curso. Sob perspectivas distintas, os dados põem em primeiro plano a diversidade constitutiva das turmas, desde a faixa etária até o vínculo com a instituição brasileira: uns cursam graduação, outros estão na pós-graduação.

Isso indica que o aspecto basilar a ser enfrentado é a heterogeneidade intrínseca das turmas de PFOL. No entanto, todas essas distinções sofrem um apagamento nos arranjos propostos pelas IES atuais. Embora exista um empenho louvável das instituições de adequar-se para atender à internacionalização, tal movimento ainda é lento e as medidas estruturais, incipientes.

Disso decorre que muitas vezes os alunos não são separados por nível de proficiência, seja porque faltam professores, seja porque faltam salas disponíveis. O número de alunos por turma também está sujeito à quantidade de docentes e salas que a escola possui.

O programa será o mesmo para todos os alunos, bem como o conteúdo e as avaliações, como ocorre nas demais disciplinas, embora as propostas de ensino contemporâneas determinem que os interesses do aluno fiquem em primeiro plano na seleção de temas trabalhados.

Outro percalço advém de o acesso à internet ficar comprometido em campi cuja acessibilidade tecnológica é incipiente, tanto no sistema de redes como em equipamentos de livre acesso a alunos e professores. É evidente que a carência dessas condiçóes no entorno invade a sala de aula e compromete $o$ processo de ensino/aprendizagem.

Além disso, em relação ao ensino de PFOL, pode-se pensar que outro arranjo físico da sala de aula poderia ser mais adequado do que as carteiras individuais arrumadas umas atrás das outras. Em adiçãao, pode ser que carteiras não sejam o mobiliário mais adequado para aulas de qualquer idioma. Sofás, poltronas, almofadas, pufes não ajudariam a criar um ambiente de descontração, propício para aprendizagem de língua estrangeira? Móveis diversificados acolheriam a diversidade de preferência dos alunos. Afinal, a 
obsessão dos professores em buscar o erro e o consequente medo de errar dos alunos, atitudes tão improdutivas para a aprendizagem, não se justificam também pelo espaço rígido, fixo, invariável, que se impõe na configuração física da sala de aula?

Quanto aos equipamentos de sala de aula, a privação fica no limite de impossibilitar o trabalho do professor: normalmente o espaço conta apenas com as já mencionadas carteiras e o quadro-negro ou branco (FURTOSO, 2009). A ausência de televisor, vídeo, enfim, equipamentos de imagem e som, tão indispensáveis no ensino de línguas, restringe em demasia as atividades. Quantas escolas oferecem laboratório de línguas para o ensino de PFOL? Com escassas salas que possuem computadores conectados à internet, todo o conteúdo da rede raramente pode ser usado como objeto educacional.

A duração das aulas também mereceria ser repensada. 90 ou 100 minutos de aula é o tempo ideal para um encontro que objetiva o ensino/ aprendizagem de língua estrangeira? Qual prática pedagógica defende o mesmo tempo de aula para conteúdos programáticos distintos? A aula de PFOL deve ter a mesma frequência de outras disciplinas, ou seja, um encontro semanal?

Nos propósitos deste artigo, essas indagações aparecem como comprovação da inadequação das escolas à diversidade cultural exacerbada pelos intercâmbios estudantis. Os recortes dispersos e transdisciplinares - ensino e tecnologia, configuração física da sala de aula, duração e periodicidade das aulas etc. - vinculam a pesquisa à área da linguística aplicada em sua versão contemporânea, cujo propósito é situar a pesquisa no mundo, propor questôes reais e lidar com dados contextualizados (MOITA LOPES, 2006; ROTH; MARCUZZO, 2008).

Assim, a proposta de internacionalização, objeto de desejo das IES da atualidade, precisa ser incorporada não apenas nos intercâmbios, mas no planejamento estratégico da instituição. Isso implica envolver todos os agentes do contexto educacional, inclusive os funcionários, que precisam ser orientados para lidar com a diversidade linguística e cultural. Implica também investimentos na estrutura física da instituição, na formação dos docentes, na preparação dos funcionários.

Essa análise demonstra como a escola está despreparada para lidar com o elemento essencial trazido pela internacionalização: a heterogeneidade. Ignorando a diversidade, a escola só sabe lidar com o igual: salas de aula iguais para todas as disciplinas, duração igual independente das distinções de conteúdo, diluição de diferenças. Essa opção pela homogeneização ocorre em todas as práticas escolares e se materializa na disciplinarização e divisão de 
saberes, procedimentos que a escola precisa resolver para se sintonizar com as demandas do século XXI. No ensino de PFOL, tema aqui considerado, essas práticas prejudicam consideravelmente a aprendizagem.

Finalizada a análise dos dados, foi possível perceber uma limitação da pesquisa: o fato de o questionário ter sido feito em língua portuguesa. Embora os alunos tenham sido orientados sobre a possibilidade de responder em inglês à questão aberta, e alguns fizeram isso, a opção pela língua inglesa na formulação poderia ter favorecido a compreensão das perguntas. Tal prática pode ser utilizada em pesquisas futuras, sobretudo nas que almejam um mapeamento inicial dos estudantes estrangeiros.

Por outro lado, a formulação das perguntas e respostas em língua portuguesa permitiu analisar, pelos arranjos linguísticos empregados, o nível de proficiência dos respondentes. Assim, parte dos dados apresentava-se não apenas no conteúdo das respostas, mas também na estrutura verbal empregada, nos elementos concretos da forma.

Perguntas e respostas em português ou em inglês, portanto, são opções de que o pesquisador pode se valer ao definir as características formais da pesquisa, sem se esquecer dos objetivos específicos de cada caso.

Nos limites deste artigo, interessa destacar os dados referentes à diversidade cultural. Da América Latina aos Estados Unidos da América, além de países da Europa, nove nacionalidades frequentaram as aulas de PFOL. As distinções culturais saltam aos olhos sob todos os aspectos, pois são países que possuem realidades socioeconômicas e níveis de desenvolvimento social bastante distintos. Essa gama de nacionalidades permaneceu no primeiro semestre de 2012 na mesma IES pesquisada, com aumento nos países da Europa e dos EUA (66\%), para 34\% da América Latina.

Tal diversidade se traduz em gestos e modos de agir diferenciados. Por isso, o entendimento sobre as experiências dos intercambistas quando se veem sós, vivendo em outro país, também traz aproveitamento para as aulas de PFOL.

\section{Após o desembarque}

Jørgen e Rikke, os personagens descritos na introdução deste artigo, jamais sentiram as alterações físicas que vivenciam desde que desembarcaram em Guarulhos, pois o clima daqui é bastante diferente daquele com o qual estão acostumados na Dinamarca. Essa experiência física básica de estar num país tropical é seguida por muitas outras. 
No começo da vida em outra localidade geográfica, tudo resulta em estranhamento. A comida, expressão cultural vigorosa na formação identitária, é diferente nos países, não só porque a produção agrícola é fortemente determinada pelo clima da regiáo, mas também porque os mesmos alimentos são preparados de forma particular, própria daquela cultura, com diferentes procedimentos culinários. Assim, o estrangeiro pode se sentir afetado na sua necessidade elementar de alimentação. Os dinamarqueses podem fazer ares de asco à simples menção da nossa vitamina de abacate batido com leite e açúcar. $\mathrm{Na}$ Dinamarca, abacate integra o cardápio de pratos salgados, sendo servido em saladas ou como finas entradas, acompanhado com camarão e molhos especiais. Assim, nas suas expressões mais elementares, "[...] a cultura diversifica a humanidade, apesar de sua unidade biológica" (ZANATTA, 2009, p. 161).

Outra experiência inusitada relaciona-se à percepção olfativa. Em outro país, até o cheiro local pode ser percebido como diferente, em decorrência das condiçôes climáticas e das características de cada região, com seus diferentes arranjos organizacionais. Embora o olfato tenha grande capacidade adaptativa, no início as diferenças, reforçadas pelos demais fatores de adaptação à nova localidade, podem incomodar, ou pelo menos aguçar o senso de estranhamento, em função de todas as alteraçóes na experiência sensorial.

Todos esses desajustes podem ser negativamente potencializados pelo $j e t$ lag: sensação de desconforto físico decorrente da diferença de fuso horário. Sobretudo nos primeiros dias, sintomas como fadiga, dor de cabeça, náusea, dificuldade de concentração etc. podem ocorrer em graus variados, dependendo de cada pessoa e da viagem em si, além de serem fortemente influenciados por aspectos psicológicos. Na ansiedade de conhecer o Brasil, é provável que Jørgen se livre mais rapidamente desses efeitos desagradáveis do que Rikke, cuja falta de motivação para a viagem pode intensificar a sensação dos danos físicos.

Além das condiçôes geográficas e climáticas concretas, o corpo biológico também sofre influências moldadas pela cultura, no sentido empregado por Edward Tylor, antropólogo britânico: "todos os itens da vida de um povo representam o universo denominado cultura" (apud DOURADO; POSHAR, 2010, p. 37).

Assim, conforme os dias passam, outros aprendizados vão ocorrendo. Rikke e Jørgen se dão conta de que no transporte público municipal há um funcionário para o qual a passagem deve ser paga. No país deles, não há cobrador em ônibus: os passageiros registram a viagem em máquinas instaladas dentro do veículo. Não há catracas/roletas a serem ultrapassadas, tampouco há 
controle ostensivo sobre o pagamento. Raramente um fiscal pode entrar no ônibus e fazer essa verificação.

De todos os contrastes, o que mais incomoda Rikke nas interaçóes com os brasileiros é o encontro e a despedida. Ela nunca sabe se deve dar beijos e, se sim, quantos. Procura aguçar a percepção e observar os brasileiros nos momentos em que eles interagem entre si, mas ela não consegue encontrar padrão na imprevisibilidade deles: às vezes dão apenas um beijo; outras vezes dois e outras, três. Há ocasiōes em que os beijos, quantos sejam, são seguidos por fortes abraços. Assim, as práticas relacionais que ela estabelece com os brasileiros são sempre motivos de preocupação, pelo receio de cometer gafes e ser mal interpretada.

Já Jørgen se chateia pelo fato de os colegas com os quais mora sempre deixarem as portas internas do apartamento abertas. Ele parece ainda ouvir constantemente a voz do pai ou da mãe: "Feche a porta do quarto!"; “Feche a porta do banheiro!"; "Feche a porta, menino!". Em país frio, as portas dos cômodos devem ser mantidas sempre fechadas, para que o aparelho de aquecedor surta efeito, ou seja, esquente o ambiente. Jørgen já percebeu que no calor do Brasil é melhor que as portas sejam mantidas abertas, para que o ar circule, mas a força do hábito o leva a fechar todas as portas dos aposentos.

Esses aprendizados ininterruptos desorientam, desestabilizam, porque o estrangeiro perde as referências que lhe davam segurança. Isso gera o choque cultural (OBERG, 2006), que será percebido de maneira muito singular: "alguns vivenciam grandes problemas de adaptação e sentem saudades de casa; outros passam o ano todo como se estivessem numa festa ininterrupta, praticamente sem se abalar com a interação entre culturas; outros ainda se adaptam bem e adquirem competência intercultural" (PEARSON-EVANS, 2006, p. 39, tradução minha). ${ }^{5}$

No entanto, qualquer que seja o impacto, não há como se livrar dessa sensação de estrangeiridade, e o intercambista carrega esse desassossego para a sala de aula. Conhecedor dessa realidade, o professor, portanto, deve se conscientizar de que os objetivos do ensino de hoje são diferentes do de décadas anteriores. Na atualidade práticas mais formativas e menos hierarquizantes podem trazer resultados melhores. Fato inquestionável é que a presença desses estrangeiros altera por completo as estruturas relacionais, as dinâmicas de

\footnotetext{
5 "Some experienced major adjustment problems and home-sickness; others sailed through the year, seeing it as one long party, virtually untouched by cross-cultural interaction; some others adjusted well and gained in cross-cultural competence."
} 
ensino, e impõe a reflexão de temas que antes não tinham presença marcante nas aulas de PFOL.

\section{Implicações para o ensino de PFOL}

A diversidade cultural nas aulas de PFOL traz particularidades que as distinguem muito do ensino de língua materna.

Inicialmente, é possível notar que o ensino de PFOL agrupa um conjunto de alunos que não têm práticas compartilhadas. Não se trata propriamente de uma turma, um grupo, como os que são facilmente identificados por um professor experiente na aula de língua materna, na qual os alunos possuem um ethos coletivo, ou seja, "hábitos locucionais partilhados por membros de uma comunidade" (MAINGUENEAU, 2008, p. 16). Segundo esse autor, "[...] existem, para um dado grupo social, ethe fixados, que são relativamente estáveis, convencionais" (2008, p. 17).

Nesse contexto, a mera compreensão sobre o que é e como age um professor também difere, conforme Hathaway:

Diferentes culturas atribuem diferentes posições aos professores. Em algumas há respeito e lealdade infindáveis para com os professores, numa aceitação inquestionável da autoridade deles, enquanto em outras há uma abordagem mais igualitária para essa profissão. (HATHAWAY, 2007, p. 230, tradução minha) ${ }^{6}$

Além disso, os alunos apresentam diferentes preferências de aprendizagem, também moldadas pela cultura. Sendo importante alicerce na formação discursiva, a cultura é elemento marcante na constituição da identidade de cada indivíduo, assim definida:

Identidade é algo complexo, não monolítico, em contínua construção nas práticas discursivas, mutante, portanto. Não é só constituída por nossa filiação, idade, nacionalidade, sexo, profissão, e outros aspectos que podem ser encontrados em nossos documentos e/ou currículo. Pela Análise do Discurso, somos descritos pela posição que ocupamos dentro do universo discursivo. Esta é definida pela formação discursiva em que estamos inseridos; é dada por nossa memória histórica. (BLATYTA, 2008, p. 109, grifo nosso)

\footnotetext{
6 "Different cultures hold 'teachers' in different positions. In some there is never-ending respect for and loyalty to teachers, in some unquestioned acceptance of the authority of teachers, while in others there is a more egalitarian, collegial approach to this profession."
} 
Por trás das singularidades de cada aluno, está a herança cultural e, em consequência, não é possível gerenciar as aulas de PFOL sem referenciar a cultura. No ambiente multicultural da atualidade, as várias culturas estão imbricadas. Sem a abordagem intercultural, é provável que surjam divergências inibidoras do processo de aprendizagem, pois "não há encontro entre culturas ou entre povos distintos sem que esteja presente uma intrincada rede de forças e tensões que são provenientes de diferentes visões de mundo. Não há encontro de diferenças sem conflito" (MENDES, 2007, p. 121).

Dependendo da maneira como o professor organiza o tempo da aula, o espaço da classe e as atividades, ele irá alcançar ou não as preferências dos alunos. Fora isso, se a distância social e cultural entre professor e alunos for muito acentuada, a realidade se tornará incomunicável. Vale lembrar também que "[...] em línguas diferentes, ou variedades diferentes de uma mesma língua, as práticas relacionais, como deixar maior ou menor distância corporal, cortar a palavra etc. diferem" (SERRANI, 2010, p. 16).

Podem-se, portanto, prever atritos, sobretudo em decorrência da escassez da perspectiva cultural nas aulas de PFOL, ainda fortemente centradas nos aspectos linguísticos (SERRANI, 2010). Para agravar esse fato, nas poucas vezes em que tem sido abordada, a cultura é tratada de forma estereotipada, com visíveis desvantagens para a aprendizagem.

De forma geral, os professores não são preparados para trabalhar a cultura nas aulas de língua e "muitas das informaçōes que transmitimos aos nossos alunos são mera repetição do senso comum, informações que repetimos quantas vezes forem necessárias sem a menor reflexão" (NIEDERAUER, 2010, p. 110). É importante, portanto, promover a ressignificação do conceito cultura e relacioná-la à construção discursiva e social.

Conceber a cultura como só tendo existência no contexto social implica reconhecer que ela é socioculturalmente construída nas práticas discursivas, nas formas de ser, dizer e agir. Essa cultura, denominada invisível, cultura que se constrói nas e pelas práticas discursivas, sendo, portanto, constitutiva da língua. (DOURADO; POSHAR, 2010, p. 42)

Sem desenvolver a sensibilidade cultural, enfrentamentos de toda ordem podem trazer entraves à aprendizagem: "[...] se não houver essa sensibilidade intercultural, a diferença cultural pode ser sentida por muitos indivíduos como sendo uma ameaça, porque oferece uma alternativa à sua visão de realidade e, desse modo, à sua identidade, ocasionando sérios conflitos culturais" (OLIVEIRA, 2012, p. 77). 
Para fugir do fundamentalismo cultural, o professor necessariamente terá que superar posturas etnocêntricas e lidar com as alterações linguísticodiscursivas decorrentes da diversidade multicultural e plurilíngue das turmas. Nas palavras de Bizzaro e Braga, "a educação intercultural, na escola, começa quando o professor ajuda o educando a descobrir-se a si mesmo. Só então este poderá pôr-se no lugar do outro e compreender as suas reacçōes, desenvolvendo empatias" (2004, p. 58).

Finkbeiner (2009) utiliza a metáfora do GPS para ilustrar esse processo de autodescoberta em outra cultura: "O GPS humano tem como ponto de partida o self. Antes de começarmos a viagem, precisamos localizar o nosso próprio self [...] Quem somos nós? Quais são os nossos valores? Quais são os nossos desejos e atitudes? Como nós nos percebemos?" (FINKBEINER, 2009 , p. 155 , tradução minha). ${ }^{7}$

Na preparação para o diálogo intercultural, atividades que possam encaminhar o autoconhecimento são bastante positivas, pois é do processo de desestabilização que será possível reconstruir-se. Nesse sentido, viver em outro país é renascer, pois implica redescobrir-se: construir sua posição no universo discursivo da sociedade em que se está, aprender a transitar em outros contextos, nos quais nem sempre se conhecem as regras.

Tais atividades devem ser ancoradas na concepção dialógica de Bakhtin (1999), que entende a linguagem como fenômeno marcadamente social, histórico e ideológico. O sujeito, portanto, constitui-se nas relaçōes dialógicas do "eu" e do "outro", nas práticas sociodiscursivas, que também são manifestaçōes da cultura.

Esse processo de autoconhecimento é a base para a criação da identidade no novo ambiente cultural, pois traz um saber social que permite que o estrangeiro possa ser atuante e útil na sociedade em que se insere. Além disso, a emergência identitária cria uma zona de conforto que estimula a aprendizagem linguística.

Dessa forma, o encaminhamento das práticas pedagógicas vai além da competência comunicativa e incentiva uma competência plurilíngue e multicultural. Afastado o ideal inalcançável de falar e agir como o nativo, cuja autoridade como modelo de perfeição já foi questionada (MCCARTHY,

\footnotetext{
7 "The Human GPS has its starting point within the self. Before we can start the navigation we have to locate the self. [...] Who are we? What are our values? What are our wishes and attitudes? How do we perceive ourselves?"
} 
2010), o estrangeiro deve ser incentivado a reconstruir a si mesmo na rede social de que participa.

Em consequência, o professor deve ser um mediador entre diferentes culturas, o que só é possível quando ele toma consciência da sua própria cultura e da maneira como se relaciona com as diferenças.

No século XXI, um professor precisa de saber identificar e distinguir os conceitos de atitudes, valores, crenças e comportamentos. Precisa de identificar, caracterizar e desmontar estereótipos culturais. Precisa, ainda, de, assumindo um ponto de vista humanista, pedagógica e cientificamente competente, se servir de formas e meios diversos de comunicação para anular preconceitos, recorrendo a estratégias educativas variadas e a metodologias que sirvam o conhecimento do EU e do OUTRO. (BIZARRO; BRAGA, 2004, p. 63)

Nessa abordagem, a concepção de língua não possui cunho estruturalista, mas sim discursiva. Inserido no discurso, o aluno pode se definir e, a partir disso, perceber o outro.

O ensino da cultura deve ser integrado ao de língua, pois pesquisas já demonstraram que a desobediência a regras sociais incomoda mais do que imprecisōes gramaticais (LAM, 2006; BORGES, 2008).

Em suma, é preciso superar a concepção monolítica de cultura e tratar do ambiente multicultural das turmas de PFOL. Isso implica suplantar informaçóes genéricas e estereotipadas sobre os povos, reconhecendo as culturas de forma dinâmica, em ininterrupto processo de atualização.

São também de grande valia as experiências do professor como estrangeiro. As viagens que ele realizou em outros países, nas quais tenha sido deslocado da sua zona de conforto, aguçam o senso de empatia em relação à situação dos alunos estrangeiros. Vivenciar outras culturas amplia a mente e mostra, no mínimo, que as peculiaridades de cada povo não devem ser vistas como ameaças, mas sim como interpretações possíveis à realidade.

\section{Considerações finais}

Este texto situou os intercâmbios estudantis como parte de um tema mais amplo: o da internacionalização das IES.

No processo de globalização vigente, há evidências de que a internacionalização educacional não deve ser apenas um modismo passageiro, mas parece ter vindo para ficar. A padronização educacional na Europa e 
América Latina ilustrou a preocupação das universidades na criação de políticas educacionais consensuais e captação de alunos estrangeiros.

Nessa conjuntura, o Brasil tem se destacado, devido ao aumento da competitividade econômica aliada a programas para a redução da desigualdade social. Isso colocou o país na rota de interesse dos estrangeiros, que vêm ao país a estudo ou a trabalho. Para maior interação na sociedade, eles buscam cursos de língua portuguesa, o que tem se configurado na ampliação da diversidade cultural e linguística das turmas de PFOL.

Dados empíricos da pesquisa realizada em IES pública demonstraram a realidade multicultural e plurilíngue decorrente dos intercâmbios estudantis em contextos universitários. A partir dessa constatação, este texto analisou as implicaçōes para as aulas de PFOL. Dentre elas, destacou-se a importância de se adotar práticas pedagógicas que integrem o ensino de língua ao de cultura, já que ambas definem nossa forma de estar no mundo. Além disso, assinalouse que o professor dará uma grande contribuição à aprendizagem ao desenvolver tarefas nas quais o aluno seja guiado a um processo gradual de autoconhecimento, de forma a criar sua própria identidade social e, a partir disso, evocar um sentimento de pertencimento e identificação. Da mesma forma, o conhecimento sobre como a sociedade alvo interage deve servir para demonstrar a improdutividade de posturas etnocêntricas, além de zelar pela convivência multicultural. Exemplos com personagens dinamarqueses mostraram que o professor deve ter consciência dos sentimentos e sensaçôes que $o$ intercambista vivencia na fase de adaptação a outra cultura, ajudandoo a integrar-se de forma atuante e participativa na sociedade alvo.

Tudo isso requer novas perspectivas teórico-metodológicas, para as quais os cursos de formação de professores devem estar atentos. Se bem preparado para a complexidade cultural que encontrará em sala de aula, o professor conseguirá promover um ensino da linguagem como prática intercultural, fundamental para um bom aproveitamento dos intercâmbios educacionais.

Finalmente, é preciso lembrar que as modificaçôes requeridas pelos novos cenários educacionais não podem ocorrer apenas no plano pedagógico. São fundamentais mudanças transversais que englobem todo o ambiente educacional, bem como todos os atores que nele atuam. 


\section{Referências}

BAKHTIN, M. Marxismo e filosofia da linguagem. Trad. Michel Lahud e Yara Frateschi Vieira. 9. ed. São Paulo: Hucitec, 1999.

BIZARRO, R.; BRAGA, F. Educação intercultural, competência plurilíngue e competência pluricultural: novos desafios para a formação de professores de línguas estrangeiras. In: SECÇÃO DE ESTUDOS FRANCESES DO DEPARTAMENTO DE ESTUDOS PORTUGUESES E DE ESTUDOS ROMÂNICOS (Org.). Estudos em homenagem ao Professor Doutor António Ferreira de Brito. Porto: Faculdade de Letras da Universidade do Porto, 2004. p. 57-69. Disponível em: <http:// ler.letras.up. pt/uploads/ficheiros/4373.pdf>. Acesso em: 15 set. 2012.

BLATYTA, D. F. O papel do professor de línguas na construção de uma aprendizagem significativa. In: SILVA, K. A.; ALVAREZ, M. L. O. (Org.). Perspectivas de investigação em linguistica aplicada. Campinas: Pontes, 2008. p. 89-116.

Bologna Process. Apresenta informações sobre os países e organizações envolvidas no processo de criação da Área Europeia de Ensino Superior. Disponível em: <http:// www.ond.vlaanderen.be/hogeronderwijs/bologna/about>. Acesso em: 10 out. 2012. BORGES, J. K. de C. "Como um touro na loja de porcelana” ou das condições comunicativas de um estrangeiro no Brasil. In: ASSIS-PETERSON, A. A. de (Org.). Linguas estrangeiras: para além do método. São Carlos: Pedro \& João; Cuiabá: UFTM, 2008. p. 77-93.

BURNETT, C.; GARDNER, J. The One Less Travelled by...: The Experience of Chinese Students in a UK University. In: BYRAM, M.; FENG, A. (Ed.). Living and Studying Abroad: Research and Practice. Clevedon: Multilingual Matters, 2006. p. 64-90.

CAPES. Ciência sem fronteiras: um programa especial de mobilidade internacional em ciência, tecnologia e inovação. Disponível em: <http://capes.gov.br/bolsas/ bolsas-no-exterior/ciencia-sem-fronteiras $>$. Acesso em: 8 out. 2012.

DOURADO, M. R.; POSHAR, H. A. A cultura na educação linguística no mundo globalizado. In: SANTOS, P.; ALVAREZ, M. L. O. (Org.). Lingua e cultura no contexto de português lingua estrangeira. Campinas: Pontes, 2010. p. 33-52.

FINKBEINER, C. Using "Human Global Positioning System" as a Navigation Tool to the Hidden Dimension of Culture". In: FENG, A.; BYRAM, M.; FLEMING, M. (Ed.). Becoming Interculturally Competent through Education and Training. Bristol: Multilingual Matters, 2009. p. 151-173.

FURTOSO, V. B. (Org.). Formação de professores de português para falantes de outras linguas: reflexões e contribuiçôes. Londrina: EDUEL, 2009. 
HATHAWAY, J. Rights, Choices and Values: Voyages through Intercultural Spaces. In: PEARSON-EVANS, A.; LEAHY, A. (Ed.). Intercultural Spaces: Language, Culture, Identity. New York: Peter Lang, 2007. p. 227-233.

JOYCE, H. Brazilian Portuguese is the Best Language. The Economist, Mar.-Apr. 2012. Disponível em: <http://moreintelligentlife.com/content/ideas/helenjoyce/brazilian-portuguese-best-language $>$. Acesso em: 19 ago. 2012.

KIM, T. Transnational Academic Mobility, Internationalization and Interculturality in Higher Education. Intercultural Education, v. 20, n. 5, p. 395405, 2009. Disponível em: <http://brunel.academia.edu/TerriKim/Papers/ 935170/ Transnational_academic_mobility_internationalization_and_ interculturality_in_higher_education>. Acesso em: 12 set. 2012.

KRAWCZYK, N. R. As políticas de internacionalização das universidades no Brasil: o caso da regionalização no Mercosul. Jornal de Políticas Educacionais, n. 4, p. 41-52, jul.-dez. 2008. Disponível em: <http://www.jpe.ufpr.br/ n4_5.pdf>. Acesso em: 23 set. 2012.

LAM, C. M. H. Reciprocal Adjustment by Host and Sojourning Groups: Mainland Chinese Students in Hong Kong. In: BYRAM, M.; FENG, A. (Ed.). Living and Study Abroad: Research and Practice. Clevedon: Multilingual Matters, 2006. p. 91-107.

LANTOLF, J. P. Sociocultural Theory and Second Language Learning. 3. ed. Oxford: Oxford University Press, 2004.

MAINGUENEAU, D. A propósito do ethos. In: MOTTA, A. R.; SALGADO, L. (Org.). Ethos discursivo. São Paulo: Contexto, 2008. p. 11-29. Disponível em: <www.editoracontexto.com.br/downloads/dl/file/id/888/ethos_discursivo_ primeiro_capitulo.pdf $+\& \mathrm{~cd}=2 \& \mathrm{hl}=\mathrm{pt}-\mathrm{BR} \& \mathrm{ct}=\mathrm{clnk} \& \mathrm{gl}=\mathrm{br}>$. Acesso em: $2 \mathrm{dez}$. 2012.

MCCARTHY, M. The Festival Incident. In: NUNAN, D.; CHOI, J. (Ed.). Language and Culture: Reflective Narratives and the Emergency of Identity. New York: Routledge, 2010. p. 140-146.

MENDES, E. A perspectiva intercultural no ensino de línguas: uma relação "entreculturas". In: ALVAREZ, M. L. O.; SILVA, K. A. da (Org.). Linguistica aplicada: múltiplos olhares. Brasília: UnB/Finatec; Campinas: Pontes, 2007. p. 119-139. MOITA LOPES, L. P. da. Linguística aplicada e vida contemporânea: problematização dos construtos que têm orientado a pesquisa. In: (Org.). Por uma linguística aplicada indisciplinar. São Paulo: Parábola, 2006. p. 85-107. MOROSINI, M. C. Estado do conhecimento sobre internacionalização da educação superior - conceitos e práticas. Educar em revista, n. 28, jul.-dez. 2006. Disponível em: <http://www.scielo.br/scielo.php?script=sci_arttext\&pid= S0104-40602006000200008>. Acesso em: 29 set. 2012. 
NIEDERAUER, M. E. F. Estranhamentos culturais em sala de aula de português para estrangeiros. In: SANTOS, P.; ALVAREZ, M. L. O. (Org.). Lingua e cultura no contexto de português lingua estrangeira. Campinas: Pontes, 2010. p. 101-121.

NÓBREGA, M. H. da. O avanço da língua portuguesa. Revista Lingua Portuguesa, São Paulo, ano 5, n. 66, p. 20-22, abr. 2011.

OBERG, K. Cultural shock: adjustment to new cultural environments. Reprint from 1960. 2006. Disponível em: <http://www.agem-ethnomedizin.de/download/ cu29_2-3_2006_S_142-146_Repr_Oberg>. Acesso em: 3 dez. 2012.

OKUMURA, R. "Invasão" de estrangeiros no Brasil aumenta demanda por cursos de língua portuguesa. Rádio Estadão ESPN. 2012. Áudio (02:19 min.). Disponível em: $<$ http://radio.estadao.com.br/audios/audio.php?idGuidSelect= 26E2DABF628941ABA27C038F9E25B6A6>. Acesso em: 3 nov. 2012.

OLIVEIRA, H. F. de. Narrativas de uma portuguesa vivendo no Brasil: algumas considerações sobre suas experiências interculturais. Revista Brasileira de Linguística Aplicada, Belo Horizonte, v. 12, n. 1, p. 73-91, 2012.

PEARSON-EVANS, A. Recording the Journey: Diaries of Irish Students in Japan. In: BYRAM, M.; FENG, A. (Ed.). Living and Study Abroad: Research and Practice. Clevedom: Multilingual Matters, 2006. p. 91-107.

ROTH, D. M.; MARCUZZO, P. Um recorte no cenário atual da linguística aplicada no Brasil. In: SILVA, K. A. da; ALVAREZ, M. L. O. (Org.). Perspectivas de investigação em linguística aplicada. Campinas: Pontes, 2008. p. 33-52.

SCHAUER, G. A. Interlanguage Pragmatic Development: The Study Abroad Context. London: Continuum, 2009.

SCHIEFFELIN, B. B.; OCHS, E. (Ed.). Language Socialization across Cultures. Cambridge (UK): Cambridge University Press, 1986.

SERRANI, S. Discurso e cultura na aula de língua: currículo, leitura, escrita. 2. ed. Campinas: Pontes, 2010.

ZANATTA, R. Abordagens de ensino de cultura na aula de português (brasileiro) para falantes de outras línguas. In: FURTOSO, V. B. (Org.). Formação de professores de português para falantes de outras linguas. Londrina: EDUEL, 2009. p. 157-181. 